This paper is the author's final peer-reviewed version of the paper published by, and subject to Institute of Physics Copyright. The full reference is:

Stability of alternating current discharges between water drops on insulation surfaces

J. Phys. D, Appl. Phys. 39 (2006) 3067-3076

S M Rowland and F C Lin

DOI: 10.1088/0022-3727/39/14/029 


\title{
Stability of Low, Alternating Current Discharges Between Water Drops on Insulation Surfaces
}

\author{
S M Rowland ${ }^{1}$ and F C Lin ${ }^{2}$ \\ ${ }^{1}$ School of Electrical and Electronic Engineering, The University of \\ Manchester, PO Box 88, Manchester, M60 1QD, UK \\ ${ }^{2}$ College of Electrical \& Electronic Engineering, Huazhong University of \\ Science and Technology, Wuhan 430074, Hubei, China \\ E-mail: s.rowland@manchester.ac.uk
}

\begin{abstract}
Discharges at the surfaces of water drops are important in the ageing of hydrophobic outdoor insulators. They may also be important in the processes leading up to flashover of these insulators in high pollution conditions. This paper considers discharges between drops when a limited alternating current is available, as experienced by an ageing insulator in service. A phenomenon is identified in which the length of a discharge between two drops is reduced through a particular type of distortion of the drops. This is visually characterised as a liquid protrusion from each of a pair of water drops along the insulator surface. This process is distinct from vibration of the drops, general distortion of their shape, and the very fast emission of jet streams seen in very high fields. The process depends upon the discharge current, the resistivity of the moisture and the insulation surface.
\end{abstract}

\section{Introduction}

Composite insulators which consist of pultruded glass cores and polymeric shedded sheaths are now deployed throughout the world and are steadily replacing the traditional ceramic and glass insulators which have been the main choice of materials over the twentieth century [1,2]. As a result, HV AC outdoor insulators are normally considered in two categories: the established ceramic insulators (glass or porcelain) and composite insulators (also called nonceramic insulators, or polymeric insulators). Physical robustness and low weight are two properties which have led to an increasing market share for composite insulators over the last 20 years.

The electrical performance of the two insulator types can also be stereotyped, and polymeric insulators with silicone rubber ( $\mathrm{SiR}$ ) sheds are widely acknowledged as providing improved performance over ceramic systems in heavily polluted or marine environments [1,2]. This is principally because of the improved wetting behaviour, through maintained hydrophobicity of the SiR, after ageing. After a period of service, wetted ceramic insulators tend to form a sheen of water on their surface as a precursor to flashover. As a result of a higher degree of hydrophobicity, composite insulators, particularly those with silicone rubber sheds, do not tend to form a uniform layer of water on their surface. The tendency on these materials is for water to remain in drops, but the drops may form 'rivulets' or 'wet fingers' of conductivity. Critical to the formation of such rivulets is the local ageing of the polymers' surface and, sometimes temporary, reduction of hydrophobicity. For this reason, since the introduction of hydrophobic polymeric insulators, a considerable body of work has been developed 
addressing electrical discharges from water drops on polymer surfaces. This has added to the extensive work previously carried out on the behaviour of water drops in electric fields.

\section{Previous work on drop behaviour on composite insulators}

Early work on the impact of electrical fields on water drops was inspired by the study of thunderstorms and much of the activity was concerned with the distortion and break-up of individual drops in high fields. These activities focused on drop instability and showed the possibility of the expulsion of high speed narrow jets of liquid from a drop [3,4,5]. Garton and Krasuki, for example, show elongation of a water drop in a silicone fluid, the drop ultimately ejecting water to restore its stability at a diminished radius [6]. Inculet and Kromann identified two modes of drop break-up in similar situations in which jets and drops can be ejected from an elongated drop in high fields [7].

That silicone rubber surfaces are more hydrophobic than traditional insulators means that individual drops of moisture on the surface are more likely to remain separate from others. This has led to a renewed period of study of individual drops over the last decade or so. Most of these studies consider drops on polymeric surfaces. One well documented feature is the recovery of hydrophobicity of silicone rubber after its surface has been aged $[8,9]$. That the drops vibrate and distort in an ac field is also well established [10-13].

It is clear that drops will interact with each other, even in the context of a highly hydrophobic surface. Again, considering cloud electrification, Latham and Roxburgh [14] modelled two drops allowing each to influence the other. They showed that the field between two spheres is enhanced beyond that associated with a single sphere by a factor of 3 if they are separated by their radius, and by orders of magnitude if they are much closer. They concluded that the external field required to disintegrate a drop is enormously reduced by the presence of a second drop.

The interaction of drops on a composite insulator is particularly important because many models of failure require drops to coalesce to form 'fingers' of conductivity which breach long lengths of the insulation surface. Karady et al describe the formation of filaments between drops on aged commercial SiR insulators, and a process by which this led to flashover of single sheds [15-17]. On ceramic systems two-dimensional sheens of water are formed between which a single dry-band tends to occur, allowing a single discharge to form on the insulation surface. Karady et al demonstrated that on composite insulators many parallel filamentary paths may be seen with their own discharges electrically in parallel with each other.

Krivda and Birtwhistle [18] showed that natural vibrations of a water drop change its shape during the AC cycle and so can effectively reduce the insulation path and increase the risk of flashover. They also point out the importance of gravity on inclined surfaces and that electric fields alone can force drops up an incline to move away from a high stress region. It was shown that when several water drops coalesce they can bridge a significant distance of insulation and descriptions are given of water drops growing so that discharges appear between them. The discharges result in loss of hydropohobicity between the drops and thus a long chain of elongated drops is formed. Joule heating at constricted points was shown to cause local breaks in the elongated drops and so discharges continuously appeared and disappeared in the chain. Phillips et al and Cheng et al have shown elongation of single water drops and also noted that drops do not gradually change their shape but rather change shape in steps and do not necessarily recover their shape after the field is removed $[19,20]$.

Lopes et al show the interaction of water drops is important in the process of partial discharges and so for ageing of insulators [21]. They calculated a field enhancement between 3.8 to 6.3 caused by the drops. A three-stage model of ageing is suggested; in the first stage hydrophobicity is maintained and there is little leakage current; in the second some discharge 
activity begins and hydrophobicity is reduced; and in the third complete loss of hydrophobicity takes place leading to aggressive dry-band discharging.

It is clear from the work discussed above that discharge activity between drops is key to the ageing of the underlying material surface. The work presented here is an experimental study of discharges between pairs of drops. The stability of such discharges is investigated for a range of water conductivities and discharge currents on a number of materials with surfaces of different orientations. Discharges have been studied with fixed voltages between water drops as might be seen on an aged insulator where long filaments of moisture already exist due to corona activity previously ageing the material.

\section{Experimental}

Most experimentation was with discharges between water drops on the top of flat horizontal surfaces. However, weathersheds of insulators are neither horizontal nor planar so some tests were carried out with drops in more complex situations, notably on the underside of surfaces. The conductivity of the water was controlled by the addition of sodium chloride. Drops were placed on the top surface of an insulator by pipette. Alternatively drops were sprayed onto the underside of insulators. In each case electrodes were inserted into suitably sized and spaced drops.

Materials of most interest for high voltage composite insulators are silicone rubbers with various additives. However, to examine the role of surface energy or hydrophobicity, a number of other materials were chosen for investigation. These were glass, PTFE and two commercial silicone rubber-based materials (SiR-1 and SiR-2). In addition a further silicone rubber was used in the form of a commercially moulded shed.

A diagram of the test circuit is shown in figure 1. Metal electrodes $C$ and $D$, which consisted of copper wire, were dipped into the drops A and B respectively. The test material was put in an enclosed chamber to prevent drafts, and both still and video cameras were used for observing and recording the movement of the drops. The gap between the two drops was kept to about $13 \mathrm{~mm}$. The metal electrodes were separated by about $25 \mathrm{~mm}$. The components shown in figure 1 include T1, a high voltage transformer, the rated voltage of which is $80 \mathrm{kV}$ $\mathrm{AC}$, and R1, a ballast resistor with values chosen to be between $1 \mathrm{M} \Omega$ and $21 \mathrm{M} \Omega$, controlling the maximum leakage current. R2 was a $1 \mathrm{k} \Omega$ current-measuring resistor. The maximum possible discharge currents are given as rms values calculated as the output voltage of T1 divided by R2. A resistant TEK P6015A HV probe was used to measure the voltage, $\mathrm{u}_{\mathrm{CD}}$, between the electrodes C and D. A Gould Classic $9500400 \mathrm{MHz}$ digital storage oscilloscope was used to monitor the waveforms of $\mathrm{u}_{\mathrm{CD}}$ and the current, $\mathrm{i}$, between the drops. The output voltage was increased by approximately $2.5 \mathrm{kV} / \mathrm{s}$ until a discharge could be ignited in every cycle.

The hydrophobicity of each material was determined by measuring the contact angle with a $0.1 \mathrm{ml}$ drop of de-ionised water. This is a particularly useful measurement in this context, since the geometry of the point of contact between the liquid, solid and air is key to controlling the processes. 


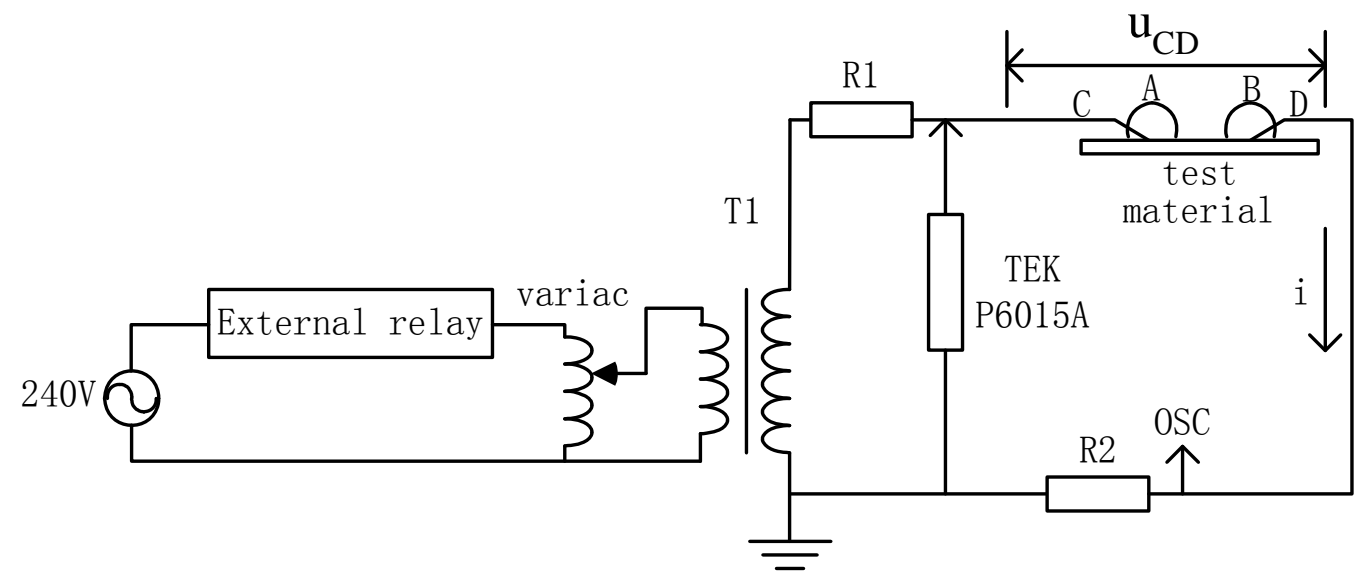

Figure 1. Diagram of the test circuit.

\section{Results}

Images of two drops on the horizontal plates, used to determine contact angle are shown in figure 2. The values of the contact angles between the water drops and surface of different materials are shown in table 1; each value given is an average of three measurements.

Table 1. Contact angles between water drops on different materials.

\begin{tabular}{l|ccccc}
\hline Material & Glass & PTFE & SiR-1 & SiR-2 & $\begin{array}{l}\text { Insulator } \\
\text { shed }\end{array}$ \\
\hline $\begin{array}{l}\text { Contact } \\
\text { angle }\left({ }^{\circ}\right)\end{array}$ & 34 & 105 & 103 & 102 & 104 \\
\hline
\end{tabular}

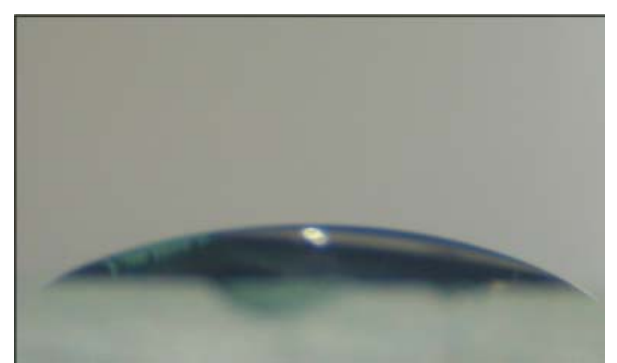

(a)

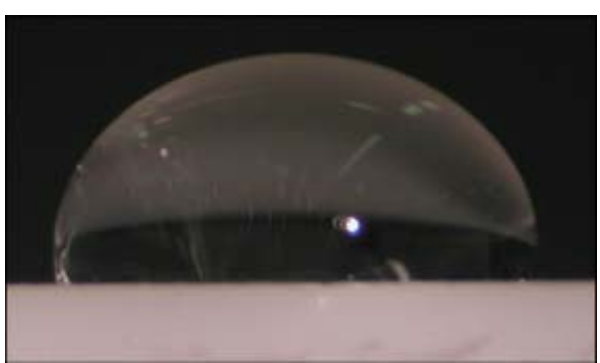

(b)

Figure 2. Water drops on (a) glass and (b) PTFE

In the experiments carried out, water was not replenished, thus evaporated water was lost from the drops. To typify how long an experiment needed to run to evaporate all the water, two $0.1 \mathrm{ml}$ water drops were dripped onto a PTFE surface. The diameter of each drop was approximately $5 \mathrm{~mm}$. The applied voltage was $6 \mathrm{kV}$, to create a discharge between the drops of $2.5 \mathrm{~mA}$. The experiment was carried out with three conductivities of water. The average drying time of the drop, each being an average of three measurements, is shown in table 2 . As each experiment was carried out, evaporation of moisture led to changes in conductivity of a drop. As thin layers of water dried this led to discharges being able to move over the surface of moisture as they became more resistive (Sections 4.6 and 4.7).

To facilitate description of the processes seen on different materials, a number of generic steps are described in table 3 , and these will then be referred to in later sections. The voltages in column 2 of table 3 are indicative of the voltage across the discharges, but these values 
vary in each case. The values given are the rms inception values determined by the TEK probe. In table 4, a comparison of which processes are seen on which materials is given. Detailed descriptions are given in sections 4.1 to 4.7 .

Table 2. Drying time of $0.1 \mathrm{ml}$ drops.

\begin{tabular}{c|ccc}
\hline $\begin{array}{c}\text { Conductivity of water } \\
\text { (mS/cm) }\end{array}$ & 0.07 (tap water) & 0.40 & 4.96 \\
\hline $\begin{array}{c}\text { Average drying time } \\
\text { (minutes) }\end{array}$ & 5.2 & 7.2 & 8.5 \\
\hline
\end{tabular}

Table 3. Typical development stages of discharges. Voltages given are indicative.

\begin{tabular}{|c|l|l|l|l|}
\hline Stage & Voltage $\mathrm{u}_{\mathrm{CD}}$ & Description & Photo & Trace \\
\hline 1 & $3 \mathrm{kV}$ & $\begin{array}{l}\text { As voltage is increased the water drops will tend to elongate } \\
\text { in the field and vibrate with the power frequency. }\end{array}$ & & \\
\hline 2 & $5 \mathrm{kV}$ & $\begin{array}{l}\text { The drops move towards each other. } \\
\text { Discharges occur, not fixed spatially, but moving over the } \\
\text { closest faces of the two drops. Electrically these discharges } \\
\text { are stable and continuous in each half cycle. }\end{array}$ & $\begin{array}{l}\text { 3b,c } \\
6 \mathrm{~b}, \mathrm{c}, \mathrm{d} \\
7 \mathrm{c}\end{array}$ & $4 \mathrm{a}$ \\
\hline 3 & $7 \mathrm{kV}$ & $\begin{array}{l}\text { Discharge roots are fixed to one spot on each drop's surface } \\
\text { and a spatially stable discharge is formed. The discharge is } \\
\text { electrically unstable in each half cycle. }\end{array}$ & $\begin{array}{l}\text { 3d } \\
6 \mathrm{~d} \\
7 \mathrm{~d},\end{array}$ & $4 \mathrm{~b}$ \\
\hline 5 & $7 \mathrm{kV}$ & $\begin{array}{l}\text { Water protrusions grow from one or each drop reducing the } \\
\text { discharge length. }\end{array}$ & $\begin{array}{l}\text { 6f,g } \\
7 \mathrm{e}, \mathrm{f}, \mathrm{g}\end{array}$ & $4 \mathrm{~b}$ \\
\hline 6 & $1-3 \mathrm{kV}$ & Flat protrusions grow, over which discharge roots roam. & & $4 \mathrm{a} / \mathrm{b}$ \\
\hline 7 & $1-3 \mathrm{kV}$ & The protrusions dry and recede but re-grow again. & $7 \mathrm{~h}, \mathrm{i}$ & $4 \mathrm{~b}$ \\
\hline 8 & & $\begin{array}{l}\text { The protrusions bridge the gap between the drops, and } \\
\text { discharges cease. }\end{array}$ & $6 \mathrm{~h}$ & \\
\hline
\end{tabular}

Table 4. A comparison of processes occurring on each material. $\checkmark, x$ and ? indicate a process generally did occur, did not occur, or were ill-defined respectively

\begin{tabular}{|c|c|c|c|c|c|c|c|c|c|c|}
\hline & \multicolumn{8}{|c|}{ Stages as defined in Table 3} & \multicolumn{2}{|r|}{ 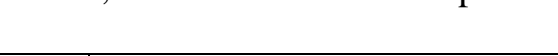 } \\
\hline Material & 1 & 2 & 3 & 4 & 5 & 6 & 7 & 8 & Fig. & Notes \\
\hline \multicolumn{11}{|c|}{ Top surface } \\
\hline PTFE & $\checkmark$ & $\checkmark$ & $\checkmark$ & $\checkmark$ & $x$ & $x$ & $x$ & $x$ & 3 & $\begin{array}{l}\text { Pits develop at discharge } \\
\text { roots after } 3 \text { minutes at } 3 \mathrm{~mA}\end{array}$ \\
\hline Glass & $\checkmark$ & $\checkmark$ & $\checkmark$ & $x$ & ? & ? & $?$ & ? & & $\begin{array}{l}\text { Drops are not stable and } \\
\text { protrusions develop quickly }\end{array}$ \\
\hline $\begin{array}{l}\mathrm{SiR} \\
>1 \mathrm{~mA}\end{array}$ & $\checkmark$ & $\checkmark$ & $\checkmark$ & $\checkmark$ & $\checkmark$ & $x$ & $x$ & $\checkmark$ & 6 & Track formed \\
\hline $\begin{array}{l}\mathrm{SiR} \\
<1 \mathrm{~mA}\end{array}$ & $\checkmark$ & $\checkmark$ & $\checkmark$ & $\checkmark$ & $\checkmark$ & $x$ & $\checkmark$ & $\checkmark$ & 6 & No track formed \\
\hline \multicolumn{11}{|c|}{ Bottom surface } \\
\hline $\begin{array}{l}\mathrm{SiR} \\
>1 \mathrm{~mA}\end{array}$ & $\checkmark$ & $\checkmark$ & $\checkmark$ & $\checkmark$ & $\checkmark$ & $x$ & $x$ & $\checkmark$ & & $\begin{array}{l}\text { Water used up rapidly. Track } \\
\text { formed }\end{array}$ \\
\hline $\begin{array}{l}\text { SiR } \\
<1 \mathrm{~mA}\end{array}$ & $\checkmark$ & $\checkmark$ & $\checkmark$ & $x$ & $x$ & $\checkmark$ & $\checkmark$ & $\checkmark$ & & $\begin{array}{l}\text { Water used up rapidly. No } \\
\text { track formed }\end{array}$ \\
\hline
\end{tabular}




\subsection{Discharge development on top of a horizontal PTFE surface}

The stages 1, 2, 3 and 4 of table 3 were followed sequentially in this case. Figure 3 shows the development of discharges on PTFE. In figure 3 (a) the voltage has not been switched on, in (b) and (c) a mobile discharge is established and in (d) the discharge has reached a fixed position, and is consequently seen as a brighter image. The state shown in figure 3(d) is reached over several seconds. Higher currents resulted in faster establishment of a stable discharge. After three minutes of high-current $(>3 \mathrm{~mA}$ ) discharge activity, there were two small pits in the PTFE at the locations of the discharge roots on the surface.

The waveform of the voltage across the electrodes and the current is shown in figure 4 . Figure 4(a) corresponds to the beginning of the discharges before the roots were fixed. When the discharge path was fixed and the current was limited, each cycle in the waveform became full of pulses, as shown in figure 4(b). When the voltage between the drops was increased (up to $25 \mathrm{kV}$, giving a maximum leakage current of $4.5 \mathrm{~mA}$ ) the rate of discharges within a half cycle also increased.

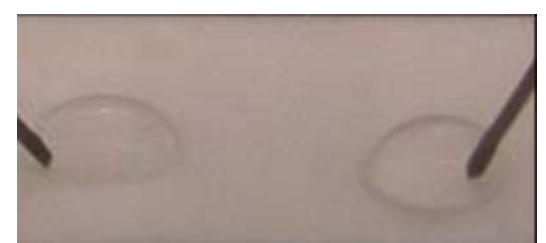

(a)

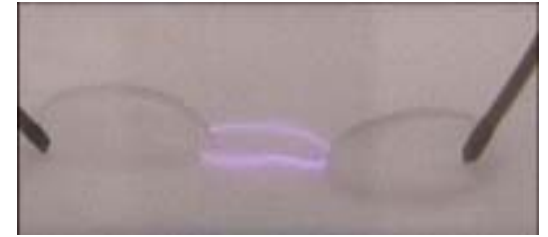

(c)

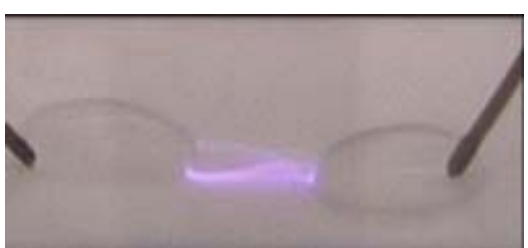

(b)

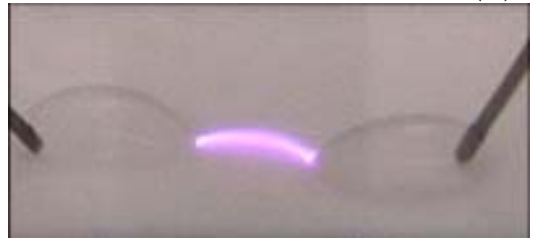

(d)

Figure 3. Development of a discharge on a PTFE surface.

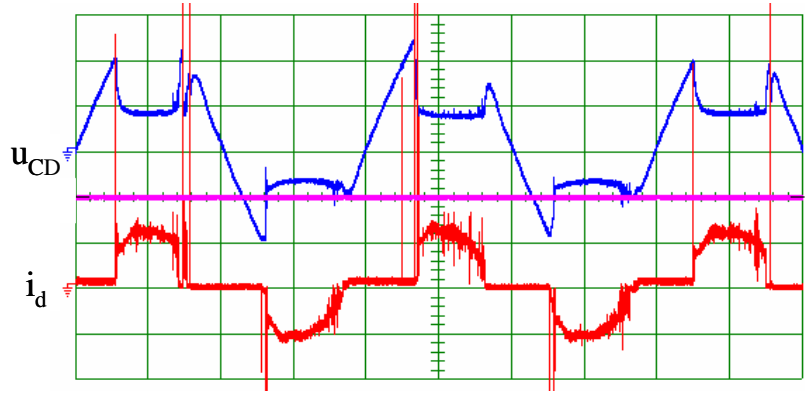

(a) Waveform of an electrically stable discharge

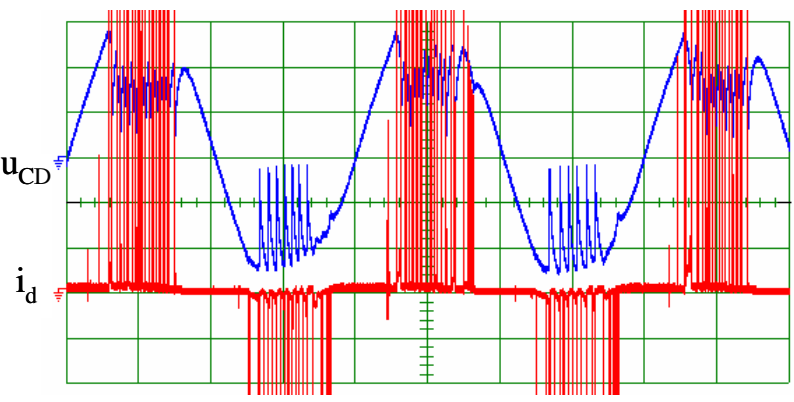

(b) Waveform of electrically unstable discharge

Figure 4. Waveforms of voltage and current on PTFE ( $\mathrm{u}_{\mathrm{CD}}$ :voltage, $\mathrm{i}_{\mathrm{d}}$ : current). 


\subsection{Discharge development on top of a horizontal glass surface}

Stable discharges rarely formed between drops larger than $0.05 \mathrm{ml}$ on glass because water spreads out, preventing distinct drops from forming. If discharging was established, the two drops joined together rapidly unless the initial drops were very flat and could spread no further. When discharges on glass between small drops were established, the water rapidly formed a protrusion at each end of the discharge. At each discharge root, water protruded from the drop face, and so the roots moved to the new tips which were then nearer to the other drop. Figure 5 shows a generic picture of the drops' shape in which the distance between protrusions of length $c$, is a, and the breadth of the front of each protrusion is b. The discharge roots moved continuously in the region between the faces of the drop protrusions, $b$, and made that region become wider and wider (i.e. b increased).

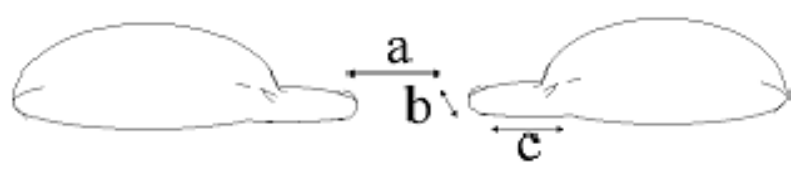

Figure 5. Schematic of protrusions between drops.

When the drops were very flat, forming a film on the surface, protrusions did not occur, but it was possible to maintain a sustained (several minutes or more) discharge between the two regions of water, the discharge moving across the adjacent faces of the wet regions. In this case, the facing edges became wider so that the range of the discharge movement was increased. The waveform became smoother when the gap became smaller, lowering the inception voltage of discharges. No visible damage to the glass was apparent after any of these experiments.

\subsection{Discharge development on top of a horizontal silicone rubber surface for currents greater than $1 \mathrm{~mA}$}

The stages 1, 2, 3 and 4 of table 3 were followed sequentially in this case. The deformation of the drops was more pronounced than that on PTFE specimens. Figure 6 shows the typical development process of a discharge with currents higher than $1 \mathrm{~mA}$. When the two drops shown in the figure were energized, they elongated in the direction of the electric field, as shown in 6(b). An intermittent discharge was ignited when the electric field was high enough, 6(c). The discharge then became continuous (occurred every cycle) when the voltage was increased further. At the beginning of continuous discharge activity, the discharge path was not fixed but moved across the face of the drops, as shown in 6(d). Then some water in the drops began to protrude from the location where the discharge roots were located, and the roots became fixed on the ends of the protrusions, 6(e). This is stage 5 in table 4 . The discharge path was then concentrated and became more luminous. As the protrusions of the water drops grew, the discharge roots moved forward so they came closer and the discharge was compressed in length, as shown in 6(f) and (g). The speed of discharge compression was higher as the protrusion lengths increased, the shorter discharge was more luminous and the dropped voltage across the discharge became lower. Eventually the discharges were extinguished, 6(h), stage 8 in table 4.

Three sizes of drop were used: $0.015 \mathrm{ml}, 0.1 \mathrm{ml}$ and $0.3 \mathrm{ml}$. There is no evidence that the volume of drops had any influence on the discharging performance. 


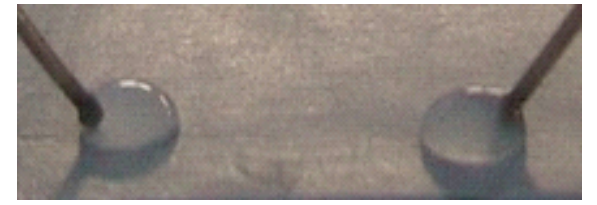

(a)

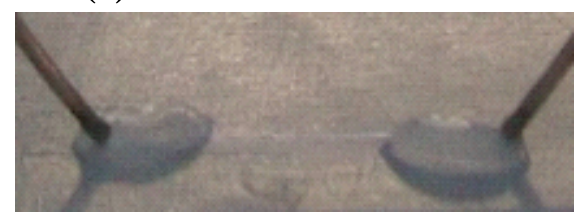

(c)

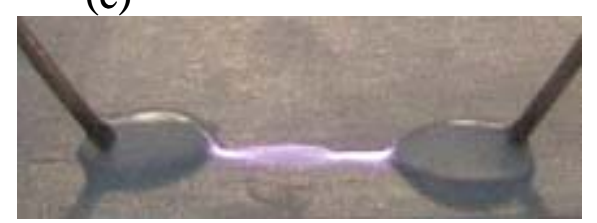

(e)

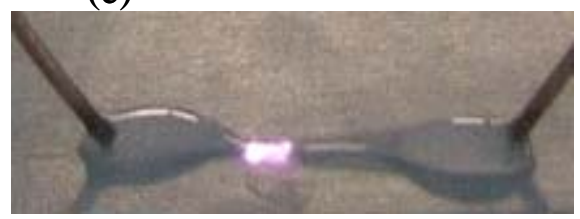

(g)

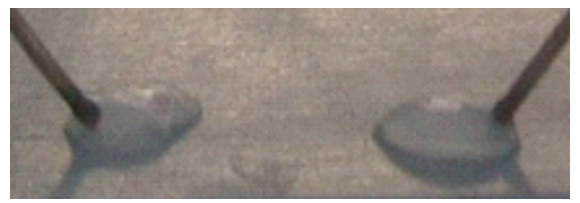

(b)

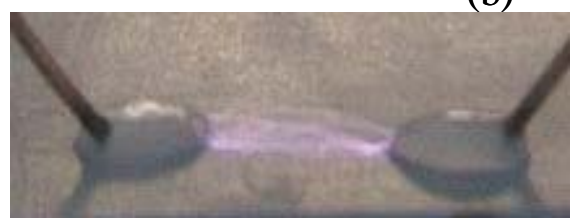

(d)

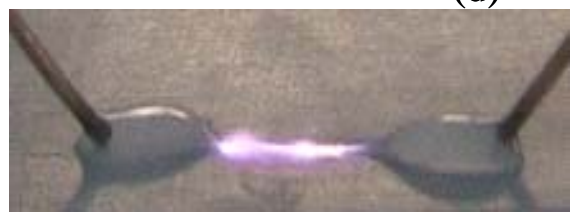

(f)

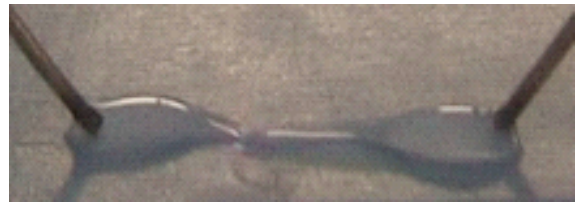

(h)

Figure 6. Discharge processes on SiR-1 with a current greater than $1 \mathrm{~mA}$.

\subsection{Discharge development on top of a horizontal silicone rubber surface for currents limited to $1 \mathrm{~mA}$}

When the current was limited to less than $1 \mathrm{~mA}$, the discharge development was different from that with a higher current. Stages 1 to 4 were similar however after discharges initiated, a thin layer of water from the drops protruded at the discharge roots, and the roots roamed over the ends of the thin protrusions, stage 6 of table 4. The protrusions extended towards each other, moving the discharge roots together. Occasionally some part of the one of the protusions was dried, and this made the discharge extend along the original path taken by the protruded water, stage 7. As time passed the height of the protusions increased, and ultimately the thicker protrusions joined together, compressing the discharge to extinction as for the higher current case, stage 8.

\subsection{Discharge Damage on top of a horizontal Silicone rubber surface}

The impact of discharges was similar on each silicone rubber material but depended on the duration and discharge current value. When the discharge current was limited below $800 \mu \mathrm{A}$, there was no track on the surface after the drops joined together. A permanent track was formed over several seconds when the current was higher than $1 \mathrm{~mA}$. The erosion became more severe with an increase of the discharge current and its duration. For example, a $3 \mathrm{~mA}$ discharge made a burn mark into the surface along the discharge path over a period of seconds when the discharge was compressed in length by the protrusions.

\subsection{Discharge development under a horizontal silicone rubber surface for currents greater than $1 \mathrm{~mA}$}

Figure 7 shows the development of discharges on the underside of a plaque, typical of the phenomenon with the current higher than 1mA. Figure 7(a) and (b) reflect stages 1, 2 and 3 of table 4. During the vibration, some water dripped down if the initial drops were large. 
Figure 7(c) and (d) show the transition from stage 3 to 4 . Discharge compression of stage 5 is illustrated in figure 7(e), (f) and (g). Occasionally the discharge was seen to elongate again as a protrusion reduced in length, as shown in $7(\mathrm{~h})$ and described as stage 7 . Eventually the discharge was gradually compressed and the two drops joined up, as shown in 7(i) and stage 8.. The longer protrusion usually came from the smaller drop. Sometimes the water in a protrusion became detached from the drop and was attracted by the opposite drop. Under such conditions, another discharge occurred between the detached protrusion and drop, as shown in figure $7(\mathrm{j})$. The duration of the discharge activity underneath the SiR was much longer than that on the top surface with the same current. A feature of this particular process is that much of the water in the drops was used up in the experiment, and little was left at the location of the original drops.

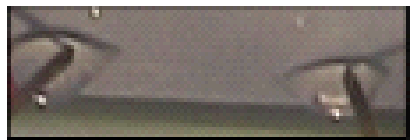

(a)

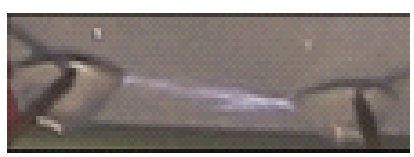

(c)

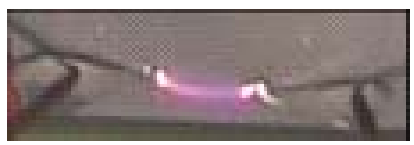

(e)

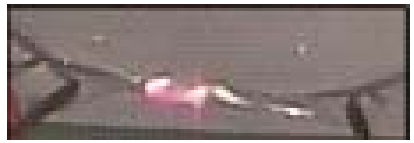

(g)

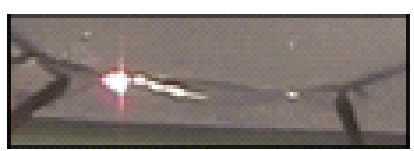

(i)

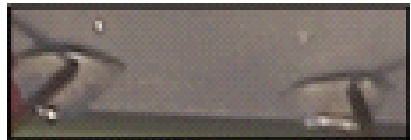

(b)

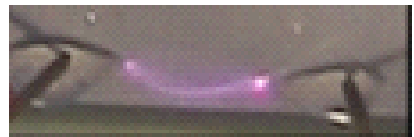

(d)

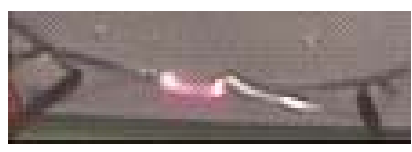

(f)

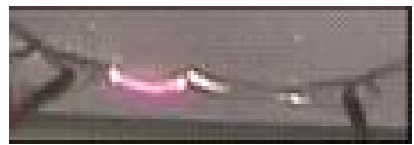

(h)

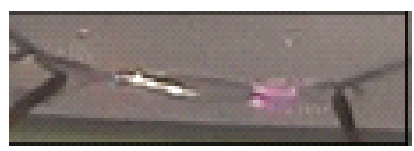

(j)

Figure 7. Development of a $2.3 \mathrm{~mA}$ discharge underneath SiR-1.

4.7. Discharge development under a horizontal silicone rubber surface for currents limited to less than $1 \mathrm{~mA}$

The stages 1 through 5 where followed much as for the high current cases. However the protusion of water was flatter and had a wider frontage, (the parameter $b$ of figure 5 was larger) so the drop and protrusion was more like a baseball cap than an igloo in shape. The protrusions continued to extend and the discharge roots continued to move across the tips of the protrusions making dimension b lager. The discharges were mainly concentrated on the areas of the protrusions facing each other. The discharge roots dried the water and made the front part of the protrusions shorter, as stage 7 . Thereafter, the water from the drops formed further protrusions and the cycle repeated itself. The voltage and current waveforms are similar to those shown in figure 4(b). 


\subsection{Discharges between shed and sheath under an insulator}

In service there is a relatively high electric field at the conjunction of the sheds and rod on a real composite insulator, shown between points A and B in figure 8, compared with along the surface of the sheds [22]. Experience shows that this is also a region where damage is often first seen. This situation was created in the laboratory. Tests with electrodes in small drops (less than $0.1 \mathrm{ml}$ ) deposited at A and B, in figure 8, showed no protrusions when the voltage was applied. Discharges continued until the drops evaporated. Larger drops fell off, before electrodes could be inserted.

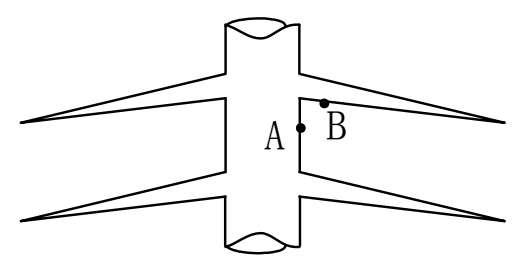

Figure 8. Sketch of a possible site for discharges on a composite insulator.

\subsection{Quantification of discharge development on silicone rubber}

The development of the protrusions can be divided into three steps. Figure 9 shows the relationship between discharge length (or distance between protrusion tips) and the time from the initiation of continuous discharging on the underside of silicone rubber. In this case the current was limited to $3 \mathrm{~mA}$. The first step was protrusion initiation; portion AB. The second step was the period during which the protrusions became thicker and grew, compressing the discharge; portion BC. The voltage and current waveforms of the discharge during both steps were similar to those in figure 4a. With the decrease of the discharge length, the speed of protrusion development became lower in the third step; portion CD. The waveforms of the voltage and current in the third step were much smoother. In this step, the rate of joining of the drops became lower again. Such steps could be identified both on the top and bottom surfaces of both SiR compounds. For the top surface, the process was invariably quicker. In general terms referring to figure 7 , region $A B$ is related to pictures $c$ and $d, B C$ to $e, f$, and $g$ and region $C D$ to $i$ and $j$. In figure 6 the region $A B$ relates to $c, d$, and e, region $B C$ to $f$, and region $\mathrm{CD}$ to g, but with a shorter time scale.

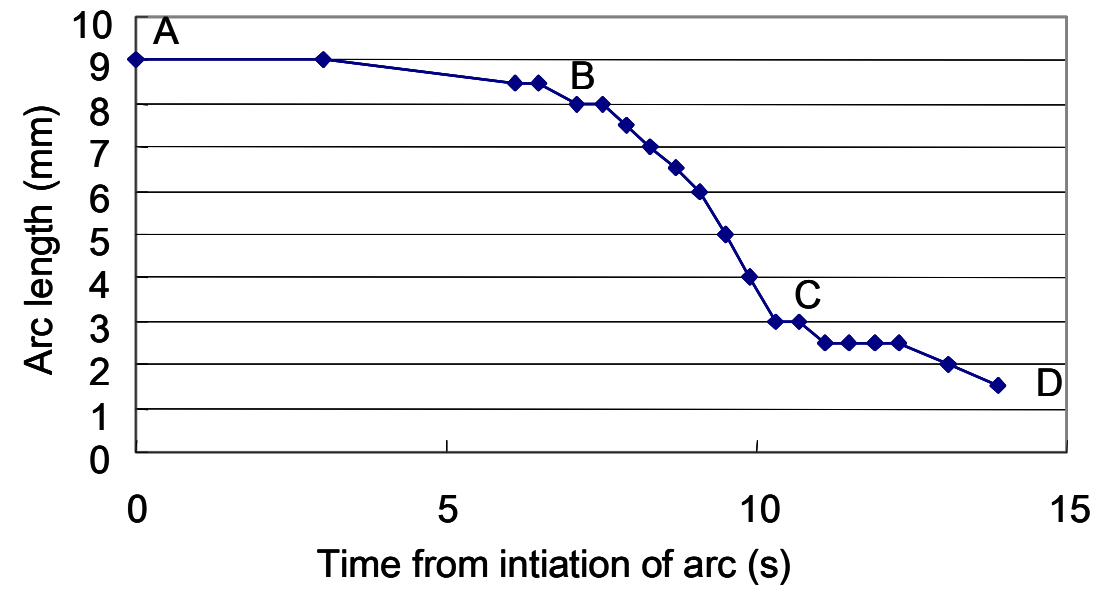

Figure 9. The discharge length as a function of time.

The discharges underneath the silicone rubber samples lasted longer than on the top, but the dependence on current and the conductivity of the water for the duration was similar. Figure 10 shows the measured durations of discharges underneath the horizontal surface with various 
current values and conductivities of water drop. The current values given are the maximum current available to the discharge as determined by the series resistor R1 in the circuit of Figure 1. Each duration plotted is an average value of three measurements under the same maximum current. There was a case in which the discharges did not extinguish under the $6.12 \mathrm{mS} / \mathrm{cm}$ and $0.8 \mathrm{~mA}$ conditions; this was omitted from the calculation but demonstrates the variability of the process. Figure 11 also illustrates the variability of these measurements using tap water (conductivity of $0.08 \mathrm{mS} / \mathrm{cm}$ ), particularly at low current levels. Figure 12 shows the relationship between the discharge current and the time taken to establish a protrusion. It can be seen that the duration of discharging increased with the decrease of current below $1 \mathrm{~mA}$. Under lower currents, the water protrusion from the drops was thinner than under higher currents. When the discharge current was lower than $300 \mu \mathrm{A}$, there was a high probability of no protrusion forming. In the case of current greater than $1 \mathrm{~mA}$, there was almost no variation in the time to create a protrusion. The discharge with tap water had a thicker visible presence than that with more conductive saline water. The roots of discharges between high conductivity drops were fixed, making the protrusions narrower than for tap water. For drops with lower conductivity, the roots covered a large area of the surface thus reducing the surface tension over a larger area enabling a wider protrusion.

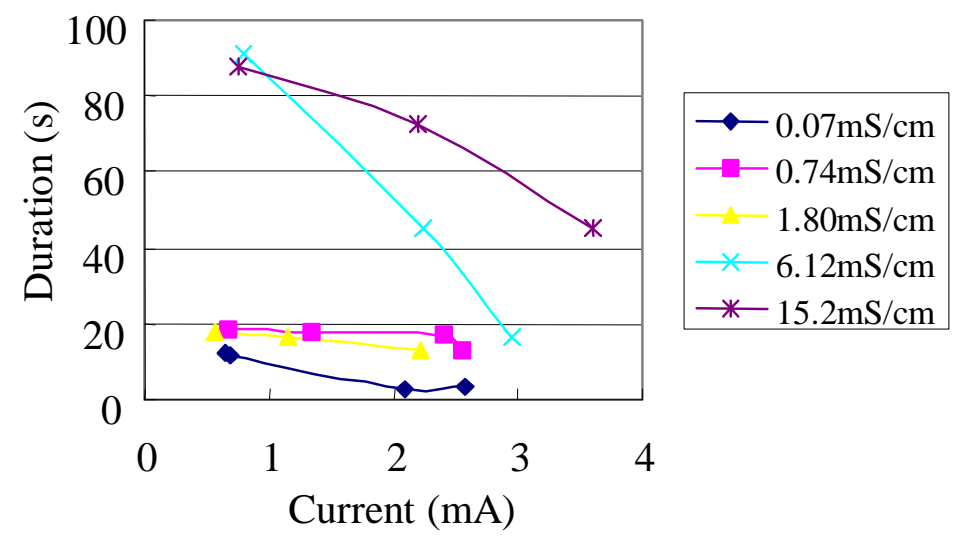

Figure 10. Effect of varying the conductivity of the liquid on the discharge current and duration (time from initiation to extinction).

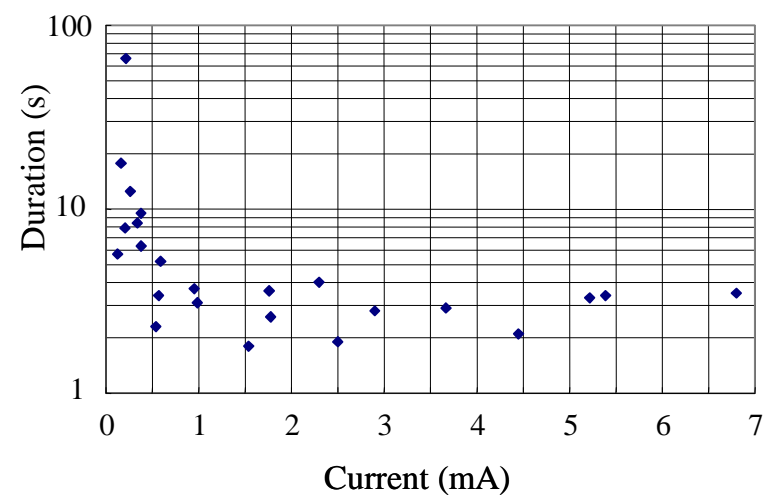

Figure 11. Variation of discharge duration (time for initiation to extinguishing through compression) for water conductivity $0.08 \mathrm{mS} / \mathrm{cm}$. 


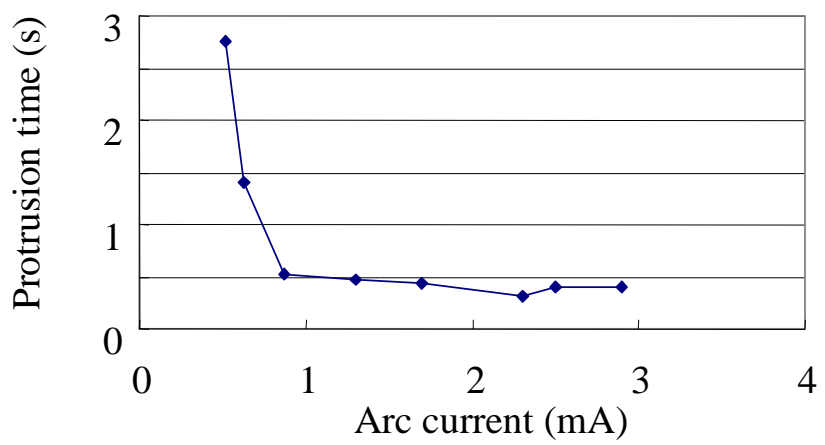

Figure 12. Variation of time taken to establish a protrusion from initial discharges.

Experiments to observe the influence of gap distance on the duration of discharging used gaps of $13 \mathrm{~mm}, 6 \mathrm{~mm}, 3 \mathrm{~mm}$ and $1 \mathrm{~mm}$ respectively. The volume of tap water drop was $0.05 \mathrm{ml}$ and the voltage was adjusted to initiate a continuous discharge. The ballast resistance was kept at $21 \mathrm{M} \Omega$. The larger the gap distance was, the greater the discharge duration. The average duration for a $13 \mathrm{~mm}$ gap was $5.8 \mathrm{~s}$, for $6 \mathrm{~mm}$ it was $2.2 \mathrm{~s}$. For $3 \mathrm{~mm}$ and $1 \mathrm{~mm}$ gaps the drops joined up in less than $1 \mathrm{~s}$, and sometimes joined up due to vibration of the drops before the discharge initiated.

\section{Discussion}

\subsection{Impact of hydrophobicity}

Table 1 shows that PTFE and SiR have almost the same angle of contact with the water drops and are consistent with those reported elsewhere [11]. That drops on PTFE did not develop protrusions suggests another property is also of importance in determining if this process occurs.

Drops of water could not form on the hydrophilic glass. As a result protrusions did not occur, rather the flat pool of water changed shape. This suggests the processes described here may only occur on polymer surfaces rather than hydrophilic ceramics. This is consistent with previous suggestions that the ageing mechanisms are different for ceramic and polymeric insulators because of alternative processes in addition to different chemical properties.

\subsection{Electrical characteristics of the discharges}

Figure 4(a) shows a classical image of a voltage and current characteristic of a discharge across an air gap. Once the discharge is struck within a half cycle it is stable and continues to burn until the extinguishing voltage is reached. In situations where there is insufficient current or voltage to maintain the discharge, the characteristics are those of figure 4(b). In this case the discharge is repeatedly switched on and off. The reason the discharge has become unstable electrically is because it has become spatially stable. Since the discharge is fixed in one position it increases its own temperature, and thereby reduces its resistivity. Since the discharge is in series with a high value resistance, if its own resistance falls it will reach a level where insufficient voltage is dropped across it for the discharge to be maintained. If the resistance of the discharge, $\mathrm{R}_{\mathrm{d}}$, is given by [1]

$$
\mathrm{R}_{\mathrm{d}}=\mathrm{A} \cdot \mathrm{I}_{\mathrm{d}}^{-\mathrm{n}}
$$

equation 1

where $\mathrm{n}$ and $\mathrm{A}$ are constants and $\mathrm{I}_{\mathrm{d}}$ is the current in the discharge, and the current is limited to

$$
\mathrm{I}_{\text {limit }}=\mathrm{V} /\left(\mathrm{R}_{\mathrm{d}}+\mathrm{R}_{1}\right)
$$


where $\mathrm{V}$ is the supply voltage, $\mathrm{R}_{1}\left(>>\mathrm{R}_{2}\right)$ is the resistor placed in the circuit shown in figure 1 and $R_{d}$ is the discharge resistance. $V_{d}$, the voltage across the discharge, is then given by

$$
\mathrm{V}_{\mathrm{d}}=\mathrm{V}-\mathrm{I}_{\mathrm{d}} \cdot \mathrm{R}_{1}
$$

equation 2

and also by

$$
\mathrm{V}_{\mathrm{d}}=\mathrm{I}_{\mathrm{d}} \cdot \mathrm{R}_{\mathrm{d}}=\mathrm{I}_{\mathrm{d}} \cdot\left(\mathrm{A} \cdot \mathrm{I}_{\mathrm{d}}{ }^{-\mathrm{n}}\right)=\mathrm{A} \cdot \mathrm{I}_{\mathrm{d}}{ }^{1-\mathrm{n}}
$$

equation 3

There is a minimum value of voltage, $V_{d}{ }^{\text {min }}$ to maintain the discharge and if $R_{1}$ is so high as to prevent sufficient current then no solution exists and the discharge will extinguish as soon as it is struck, only be struck again once the voltage has recovered.

Thus a discharge which is stable electrically when moving about may become unstable once it is forced to locate in one place. This is the situation observed in figure 4. In any case if insufficient current is available the discharge will not be stable within each half cycle; this was the case where the current was limited to $0.8 \mathrm{~mA}$. At present no explanation is offered for the small differences seen in the positive and negative half cycles.

It is clear the formation of protrusions from water drops, which lead to cessation of discharges, is material- and current-dependent. The suggestion that the reduction in physical discharge length and the stability of discharges within a cycle is important in ageing processes has been made previously by Rowland et al $[23,24]$ in the case of simpler cable geometries.

The drying times of the $0.1 \mathrm{ml}$ drops between which a discharge was struck varied with water conductivity (table 2). This is to be expected since the Joule heating in each drop will depend upon its conductivity. Drops on the bottom surfaces of materials are limited in size, and in the laboratory it was shown that the process of joining the drops readily consumed the available water. This may mean that fingers of moisture form differently on the top and bottom surfaces of composites.

The presence of a low-current discharge between water drops on SiR led to the occurrence of protrusions and thus reductions in the resulting discharge length, and an increase in its localisation. This discharge root localisation is believed to increase the temperature of the discharge column, and certainly increases its impact on the surrounding material. One other consequence of this spatial stability is, as described above, the discharge becomes less stable electrically. This in turn means that the power frequency current is reduced and high frequency current increases. Thus by locating the discharge roots less electrical energy may do more damage. Lower power frequency current may be measured during this hotter phase of discharge activity.

\subsection{The difference between discharge development on the top and bottom surfaces}

Discharges on the underside of SiR tended to follow a similar pattern to that on the top side, but generally happened more slowly. This means that activity lasted longer and we might expect therefore that damage would be greater. The detachment of a protrusion from a drop to form a separate drop was only seen underneath a surface. This detachment of a small drop from a larger drop is a well-recorded feature in high electric fields and is understood as a means of a large drop reducing its energy. Yamashita et al [25] showed a drop situated between two electrodes extend in both directions and at high fields, first vibration occurred and then minute drops were ejected along the surface. The extension of the drop shown is similar to what is reported here, but in a much shorter time-frame of $100 \mathrm{~ms}$ and in the context of isolated drops between electrodes. Higashiyama et al report emission of small drops in DC fields on PTFE also over periods of $100 \mathrm{~ms}$ [26]. The mechanism reported in this paper is much slower than that reported previously, but the physical geometry appears similar to that reported by Higashiyama. 
The lower amounts of water on the underside of the insulators due to the smaller size of water drops, and the lack of hydrostatic force feeding the protrusions led to the protrusions sometimes drying out. This created mini dry-bands and occasional short periods of discharge after the protrusions had joined the drops underneath the insulators, as shown in figure 7.

\subsection{Duration of discharge events}

It can be seen from figure 10, that the duration of an discharge event (the time taken for the protrusions to link the water drops) decreased with an increase of the available current. The duration was also reduced by decreasing the drop conductivity. Both these factors increase the field in the drop. Thus it may be that increasing the field in the drop increases the rate of growth of the protrusion, thereby decreasing the discharge duration. Zhu et al [27] previously showed corona onset for a single drop of water decreases with conductivity. Such discharges are likely to occur at the drop edges and cause a loss of hydrophobicity and thus to further drop elongation. This mechanism has not been studied here but may account for the observation that the contact angle at the root became smaller as a protrusion grew. This may also have been due to many variables such as salt concentration, temperature and field increase. Changes in contact angles on polymers are widely reported and may have many causes, and are particularly time dependent for silicone rubber [9].

Low currents lead to longer times to protrusion, slower protrusion extension and longer discharge periods. The protrusions also appear to be thinner for low currents. The duration of the discharges do not seem to be changed significantly when the conductivity of the water is greater than $0.5 \mathrm{mS} / \mathrm{cm}$.

Particularly aggressive discharges will occur if the conditions are suitable for spatially and electrically stable discharges. In these circumstances there must be sufficient current available to keep the discharge struck within each cycle, and some physical feature such as the emergence of protrusions to fix the roots spatially. Previously these conditions have been suggested as key to the ageing of dielectric self-supporting cables on HV transmission lines $[23,24]$. If the field in the discharge is less than in the drop, the discharge is able to move over the drop surface [28] and so not be fixed spatially, the mechanism by which flashover may occur [29]. The relationship between the resistance limiting the current (i.e. the resistance of the rest of the insulator surface) and the local resistance per unit length of the moisture is thus key to spatial localisation.

In the situation on a commercial insulator under the boundary between the shed and the sheath no protrusions were seen to grow. This may be because the field which is driving the protrusions from the drops is not parallel with the material surface. Many researchers have modelled the impact of a single drop [30,31] and pairs of drops [14,32-35] on the field at the drop surface for isolated drops and drops on dielectric surfaces. It is clear from this body of work that the stability of one drop is heavily affected by the presence of another. Further work is required to determine whether the process identified here occurs on commercial insulators in field conditions.

\subsection{A model for the development of discharges}

The experimental results show that a discharging process on a SiR surface can be divided into six steps:

1. the low-level deformation of drops

2. initiation of mobile discharges

3. protrusion appearance

4. spatial localisation of discharges

5. protrusion extension

6. the merger of the two drops leading to discharge cessation

The duration of discharge activity depends upon the rate of initiation and movement of the 
protrusions.

The initiation of a protrusion from a drop is a result of the combined effect of multiple tensions, as can be understood from figure 13. This is the classical representation of the forces on the drop $[9,18]$. The forces or boundary tensions at the interface of the water, dielectric surface and air are written $F_{s-g}, F_{s-l}$ and $F_{l-g}$ respectively. When there is no electric field, the stationary water drop on a horizontal surface is in equilibrium under the effect of the three forces, that is

$$
F_{s-g}=F_{s-l}+F_{l-g} \cos \theta
$$

where $\theta$ is the contact angle between the drop and solid surface.

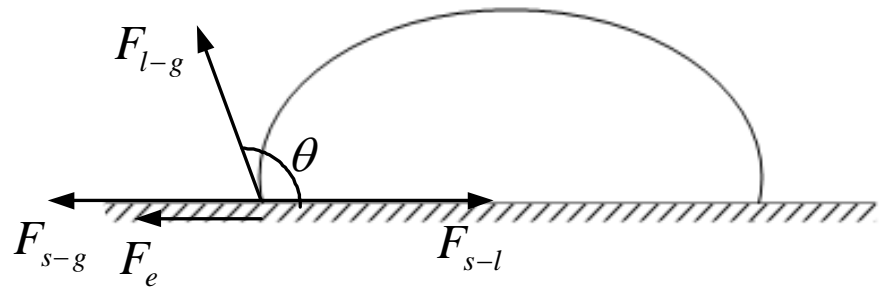

Figure 13. Forces on the base of a drop.

When the electrodes around which the drops are located are energized, an electrostatic force, $F_{e}$, occurs, also shown in figure 13. Under the influence of this force, the drop is deformed and vibrates in the direction of the electric field. Part of the drop may also slip forward. With the increase of voltage, discharges initiate, and the water at the discharge root is heated. The presence of the discharge moderates the value of the field and so $F_{e}$. The surface tension $F_{l-g}$ becomes lower with the increase of temperature, tending to zero at the discharge root. If the four forces are not in equilibrium,

$$
F_{s-g}+F_{e}>F_{s-l}+F_{l-g} \cos \theta
$$

and water will protrude from the drop at the discharge root.

There are two opposing processes in the growth of a protrusion: one is the addition of water, the other is the drying of water by discharge root heating and Joule heating in the protrusion. The ability of a protrusion to remain or grow depends on the competition between the drying speed and the rate of addition of water. If the two opposing processes reach equilibrium a discharge will continue to burn.

For a discharge with a current of less than $1 \mathrm{~mA}$, the initial protrusions are a thin layer of water. Being heated, the water tends to dry, effectively shortening the thin protrusions, so the discharges move back and forward along the protruded water. In turn, more water from the drops is added to the thin protrusions, and they become thicker. The growth of the length of the protrusions is then relatively slow. For a current higher than $1 \mathrm{~mA}$ or between highly conductive drops, the movement is faster. The evaporation of water at the discharge roots is much less than the supplement rate to the thick protrusions, resulting in faster protrusion growth.

The main difference between discharge activity on upper and lower surfaces is due to gravity. For a drop on the top surface of an insulator there is a hydrostatic force at the base of the drop, depending upon its height. This force, pushing water out at the base of the drop, is absent in a drop on the underside of a surface. Thus protrusions will tend to grow faster and 
be 'fed' with water more readily from drops on the top side of insulation. Therefore the growth of the protrusions underneath will be slower than that on the top of the plate, resulting in a longer duration of discharge activity. In any case when the gap between two protrusions becomes very small, the initial discharge voltage becomes very low too. Therefore the electrostatic force is lower than before, also reducing the rate of growth of the protrusions. This extended period of ageing on the bottom surface leads to the prediction that ageing is faster on the bottom surface since it is exposed to greater periods of discharge activity.

\section{Conclusions}

A mechanism has been identified which limits the durations of low current discharges between water drops on SiR insulation. The currents studied have been in the range of $4 \mathrm{~mA}$ and below, the order of magnitude expected on polluted outdoor insulators. The discharge duration is limited by protrusions emerging from the water drops. These protrusions fix the location of the discharge roots and thereby modify the discharge properties. Such a discharge recurs in successive half cycles over periods of a few seconds to many tens of seconds, depending upon the current available and the conductivity of the water drops. This process can occur on the top or bottom of a horizontal surface.

The formation of the protrusions from the drops changes a discharge from being an electrically stable one which moves position continuously, to one which is electrically unstable, but is spatially fixed. The latter case is more aggressive to the material on which the drops sit because it raises the local temperature at the discharge roots.

The process of protrusion formation from drops prevents long periods of discharge activity at currents over $1 \mathrm{~mA}$. However, experiments show that protrusion occurs less swiftly on the underside of an insulator, thus exposing the underside to longer periods of discharge. The process occurs more rapidly with low conductivity drops, probably because the field is then higher within the drop.

The impact of the mechanism described on the ageing of insulation systems is not clear. The effect has been created by energising drops directly, and not by putting drops on a long insulator within an electric field as would be seen in service. Further work is required to clarify this aspect, and to relate the discharge activity to material ageing.

\section{References}

[1] Looms J S 1988 Insulators for High Voltages (Peter Peregrinus/IEE)

[2] Swift D A 2004 Insulators for Outdoor Applications from Advances in High Voltage Engineering, ed. Haddad A and Warne D F (IEE, ISBN 085296158 8)

[3] Zeleny J 1917 Instability of electrified liquid surfaces Phys Rev 10 1-6

[4] Macky W A 1931 Some investigations on the electric deformation and breaking of water drops in strong fields Proc Roy Soc London A133 565-87

[5] Taylor G 1964 Disintegration of water drops in an electric field Proc Roy Soc London A280 383-97

[6] Garton C G and Krasuki Z 1964 Bubbles in insulating liquids: stability in an electric field Proc Roy Soc London A 280 211-26

[7] Inculet I I and Kromann R 1989 Break-up of large water droplets by electric fields IEEE Trans on Industry Applications 25 945-8

[8] Simmons S, Shah M, Mackevich J and Chang R J 1997 Polymer outdoor insulating materials. Part III - Silicone elastomer considerations IEEE Electrical Insulation Magazine 13 25-32

[9] Bhana D K and Swift D A 1994 An investigation into the temporary loss of hydrophobicity of some polymeric insulators and coatings $4^{\text {th }}$ Int Conf on Properties and Applications of Dielectric Materials, Brisbane Paper 5208 
[10] Yamada T, Sugimoto T, Higashiyama Y, Takeishi M and Aoki T 2003 Resonance phenomena of a single water droplet located on a hydrophobic sheet under ac electric field IEEE Trans Industrial Applications 39 59-65

[11] Higashiyama Y, Yamada T and Sugimoto T 1999 Vibration of water droplet located on a hydrophobic sheet under ac field Proc of IEEE IAS Annual Meeting, Pheonix 1825-30

[12] Higashiyama Y, Yamada T, Sugimoto T 2002 Effect of resonance of a water droplet located on a hydrophobic sheet on ac flashover Proc of IEEE IAS Annual Meeting. Pittsburg, 2198-203

[13] Schutte T and Hornfeldt S 1990 Dynamics of stressed water drops on insulating surfaces IEEE Int Symp on Electrical Insulation, Toronto 202-7

[14] Latham J and Roxburgh I W 1966 Disintegration of pairs of water drops in an electric field Proc Roy Soc A295 84-97

[15] Karady G G 1999 Flashover mechanism of non-ceramic insulators IEEE Trans DEI 6 718-23

[16] Karady G G, Shah M and Brown R L 1995 Flashover mechanism of silicone rubber insulators used for outdoor insulation 1 IEEE Trans Power Delivery 1965-71

[17] Shah M, Karady G G and Brown R L 1995 Flashover mechanism of silicone rubber insulators used for outdoor insulation - II IEEE Trans Power Delivery 10 1972-8

[18] Krivda A and Birtwhistle D 2001 Breakdown between water drops on wet polymer surfaces IEEE Conf on Electrical Insulation and Dielectric Phenomena, Ontario 57280

[19] Phillips A J, Childs D J and Schneider H M 1999 Ageing of non-ceramic insulators due to corona from water drops IEEE Trans Power Delivery 14 1081-9

[20] Cheng Z X, Liang X D, Zhou Y X, Wang S W and Guan Z C 2003 Observation of corona and flashover on the surface of composite insulators IEEE Powertech Conf, Bologna 23-6

[21] Lopes I S J, Jayaram S H and Cherney E A 2001 Partial discharge patterns from water droplets on a silicone rubber insulating surface IEEE Trans DEI 8 262-8

[22] Que W and Sebo S A 2002 Typical cases of electric field and voltage distribution calculations along polymer insulators under various wet conditions IEEE Conference on Electrical Insulation and Dielectric Phenomena, Cancun, 840-3

[23] Rowland S M and Nichols I V 1996 Effect of dry-band arc current on ageing of selfsupporting dielectric cables in high fields IEE Proc Sci Meas Technol. 143 10-4

[24] Rowland S M and Easthope F 1993 Electrical ageing and testing of dielectric selfsupporting cables for overhead power lines IEE Proc A, 140 351-6

[25] Yamashita S, Hashigushi T, Anami N, Otsubo M, Honda C, Takenouchi O, Hashimoto Y and Nakamura M 2001 Behaviour of water droplets and their charged distribution on polymer surface Proc Int Symp Electrical Insulation, Himeji 59-62

[26] Higashiyama Y, Yanase S and Sugimoto T 1998 Behaviour of water droplets located on hydrophobic insulating sheets under dc field Proc of IEEE IAS Annual Meeting, St Louis 1808-13

[27] Zhu Y, Yamashita S, Anami N, Otsubo M, Honda C and Hashimoto Y 2003 Corona discharge phenomenon and behaviour of water droplets on the surface of polymer in the AC electric field $7^{\text {th }}$ Int Conf on Properties and Applications of Dielectric Materia,l Nagoya 638-641

[28] Swift D A 1994 Flashover of an insulator surface in air due to polluted water droplets $4^{\text {th }}$ Int Conf on Properties and Applications of Dielectric Materials 550-3

[29] Hampton B F 1964 Flashover mechanism of polluted insulation Proc IEE 111 985-90

[30] Que W and Sebo S A 2002 Typical cases of electric field and voltage distribution calculations along polymer insulators under various wet conditions IEEE Conf on Electrical Insulation and Dielectric Phenomena, Cancun, 840-3

[31] Phillips A J, Jandrell I R and Reynders J P 1966 Consideration of corona onset from a water drop as a function of air pressure IEE Proc. Sci. Meas. Tech. 143 125-30 
[32] Zixia C, Xidong L, Yuanxiang Z, Shaowu W and Zhcheng G 2003 Study of water droplet discharge by electric field computation and high speed video Proc $7^{\text {th }}$ Int Conf on Properties and Applications of Dielectric Materials, Nagoya 820-3

[33] El-Kishky H and Gorur R S 1996 Electric field and energy computation on wet insulating surfaces IEEE Trans DEI 3 587-93

[34] El-Kishky H and Gorur R S 1996 Electric field computation on an insulating surface with discrete water droplets IEEE Trans DEI 3 450-6

[35] Sundararajan R, Sundhar S and Asokan T 1999 Electrohydrodynamics of water droplets on polymer surfaces IEEE Trans DEI 11 1817-24 